\title{
The effects of vegetable pickling conditions on the dynamics of microbiota and metabolites
}

\author{
Kazunori Sawada $^{1}$, Hitoshi Koyano ${ }^{2}$, Nozomi Yamamoto ${ }^{2}$, Takuji Yamada ${ }^{\text {Corresp. } 2}$ \\ 1 Innovation Division, Gurunavi, Inc., Chiyoda-ku, Tokyo, Japan \\ 2 School of Life Science and Technology, Tokyo Institute of Technology, Meguro-ku, Tokyo, Japan \\ Corresponding Author: Takuji Yamada \\ Email address: takuji@bio.titech.ac.jp
}

Background. Salting is a traditional procedure for producing pickled vegetables. Salting can be used as a pretreatment, for safe lactic acid fermentation and for salt stock preparation. This study aimed to provide valuable knowledge to improve pickle production by investigating the dynamics of microbiota and metabolites during the pretreatment and salt stock preparation processes, which have previously been overlooked. The differences in these process conditions would be expected to change the microbiota and consequently influence the content of metabolites in pickles.

Methods. Samples, collected from eight commercial pickle manufacturers in Japan, consisted of the initial raw materials, pickled vegetables and used brine. The microbiota were analyzed by $16 S$ rRNA sequencing and the metabolites quantified by liquid chromatograph-mass spectrometry. Statistical analyses helped to identify any significant differences between samples from the initial raw materials, pretreatment process and salt stock preparation process groups.

Results. Under pretreatment conditions, aerobic and facultative anaerobic bacteria were predominant, including Vibrio, a potentially undesirable genus for pickle production. Under salt stock preparation conditions, the presence of halophilic bacteria, Halanaerobium, suggested their involvement in the increase in pyruvate derivatives such as branched-chain amino acids (BCAA). PICRUSt analysis indicated that the enhanced production of BCAA in salt stock was caused not by quantitative but by qualitative differences in the biosynthetic pathway of BCAA in the microbiota.

Conclusion. The differences in the microbiota between pretreatment and previously studied lactic acid fermentation processes emphasized the importance of anaerobic conditions and low pH under moderate salinity conditions for assuring safe pickle production. The results from the salt stock preparation process suggested that the Halanaerobium present may provide a key enzyme in the BCAA biosynthetic pathway which prefers NADH as a coenzyme. This feature can enhance BCAA production under anaerobic conditions where NADH is in excess. The effects shown in this study will be important for adjusting pickling conditions by changing the abundance of bacteria to improve the quality of pickled vegetables. 


\title{
1 The effects of vegetable pickling conditions on the 2 dynamics of microbiota and metabolites
}

3

4

5

6

7

\author{
Kazunori Sawada ${ }^{1}$, Hitoshi Koyano², Nozomi Yamamoto², Takuji Yamada ${ }^{2}$ \\ ${ }^{1}$ Innovation Division, Gurunavi, Inc., Toho Hibiya Building, 1-2-2 Yurakucho, Chiyoda-ku, \\ Tokyo, 100-0006, Japan \\ ${ }^{2}$ School of Life Science and Technology, Tokyo Institute of Technology, 2-12-1 Ookayama, \\ Meguro-ku, Tokyo, 152-8550, Japan
}

Corresponding Author:

Takuji Yamada ${ }^{1}$

${ }^{1}$ School of Life Science and Technology, Tokyo Institute of Technology, 2-12-1 Ookayama, Meguro-ku, Tokyo, 152-8550, Japan

Email address: takuji@bio.titech.ac.jp

\section{Abstract}

Background. Salting is a traditional procedure for producing pickled vegetables. Salting can be used as a pretreatment, for safe lactic acid fermentation and for salt stock preparation. This study aimed to provide valuable knowledge to improve pickle production by investigating the dynamics of microbiota and metabolites during the pretreatment and salt stock preparation processes, which have previously been overlooked. The differences in these process conditions would be expected to change the microbiota and consequently influence the content of metabolites in pickles.

Methods. Samples, collected from eight commercial pickle manufacturers in Japan, consisted of the initial raw materials, pickled vegetables and used brine. The microbiota were analyzed by 16S rRNA sequencing and the metabolites quantified by liquid chromatograph-mass spectrometry. Statistical analyses helped to identify any significant differences between samples from the initial raw materials, pretreatment process and salt stock preparation process groups.

Results. Under pretreatment conditions, aerobic and facultative anaerobic bacteria were predominant, including Vibrio, a potentially undesirable genus for pickle production. Under salt stock preparation conditions, the presence of halophilic bacteria, Halanaerobium, suggested their involvement in the increase in pyruvate derivatives such as branched-chain amino acids (BCAA). PICRUSt analysis indicated that the enhanced production of BCAA in salt stock was caused not by quantitative but by qualitative differences in the biosynthetic pathway of BCAA in the microbiota.

Conclusion. The differences in the microbiota between pretreatment and previously studied lactic acid fermentation processes emphasized the importance of anaerobic conditions and low $\mathrm{pH}$ under moderate salinity conditions for assuring safe pickle production. The results from the 
40

41

42

43

44

45

46

47

48

49

50

51

52

53

54

55

56

57

58

59

60

61

62

63

64

65

66

67

68

69

70

71

72

73

74

75

76

77

78

79

salt stock preparation process suggested that the Halanaerobium present may provide a key enzyme in the BCAA biosynthetic pathway which prefers NADH as a coenzyme. This feature can enhance BCAA production under anaerobic conditions where NADH is in excess. The effects shown in this study will be important for adjusting pickling conditions by changing the abundance of bacteria to improve the quality of pickled vegetables.

\section{Introduction}

Pickled vegetables are produced using knowledge accrued since ancient times (Bautista-Gallego et al., 2013; Chakraborty \& Roy, 2018). Although the modern food industry makes pickles using refrigeration technologies and chemical additives, they are still made with salt (sodium chloride) and vinegar (acetate) (Lupien \& Lin, 2004). In particular, pickling techniques using salt have the longest history and have been used globally (Li \& Hsieh, 2004; Behera et al., 2020). Pickling processes using salt can be categorized into three groups: pretreatment, safe lactic acid (Lac) fermentation, and salt stock preparation. The pretreatment process reduces the water content of the raw materials through the dehydration effect of salt and softens the texture of the raw materials. During the pretreatment process, the juice from the pickled raw materials lowers the concentration of salt in the brine. The diluted brine is thus unable to suppress the growth of undesirable microorganisms for long-term pickling. Therefore, pretreatment is used as an independent short-term process, or as part of a long-term process with an initially high salt content or with the continuous addition of salt (Uthpala et al., 2019). Korean kimchi uses an independent pretreatment process before pickling in spicy brine (Jung et al., 2011). The fermentation process is mainly performed by lactic acid bacteria (LAB) that are relatively resistant to salt. The typical salt content for Lac fermentation is $2-5 \%$ to repress the growth of undesired microorganisms (Behera et al., 2020). Lac produced by fermentation decreases the $\mathrm{pH}$ of the brine, which reduces the growth of acid-sensitive microorganisms, further enhancing the storability of the product. The salt stock preparation process also uses high salinity brine to increase storability. The salinity of the brine can be up to $20 \%$, where limited halotolerant microbes can survive. Therefore, salt stock preparation is aimed at preservation of vegetables rather than fermentation (Behera et al., 2020). Pickling processes are still very important and of worldwide interest for researchers.

The most extensively studied pickles are sauerkraut (Plengvidhya et al., 2007; Zabat et al., 2018), cucumber pickles (Pérez-Díaz et al., 2017; McMurtrie et al., 2019; Pérez-Díaz et al., 2020), Korean kimchi (Jung et al., 2011; Jeong et al., 2013; Hong et al., 2016; Lee et al., 2017; Seo et al., 2018), and Chinese paocai (Xiao et al., 2018; Liu et al., 2019; Wang et al., 2020) and suancai (Yang et al., 2014; Wu et al., 2015) that are produced through fermentation processes. The microbiota of these pickles during the production have been previously studied using culture dependent and independent methods (Table 1). Although the microbiota in each type of pickle are not identical, almost all studies reported that the predominant genus was Lactobacillus or Leuconostoc, regardless of the pickling time. The studies of Korean kimchi revealed that pickling salinity is a key factor deciding which genus is predominant under the fermentation 
80 conditions; the lower the salinity, the higher the relative abundance of Leuconostoc (Lee et al.,

81

82

83

84

85

86

87

88

89

90

91

92

93

94

95

96

97

98

99

100

101

102

103

104

105

106

107

108

109

110

111

112

113

114

115

116

117

118
2017). The changes in concentrations of amino acids and organic acids during pickle fermentation were also studied as they relate to taste and flavor. The main fermentation product is Lac produced by LAB. Heterolactic fermentation LAB produce other various organic acids such as acetic and propionic acid. LAB may also increase amino acid concentrations by excreting peptidase that digests proteins, producing amino acids (Liu et al., 2010). Different amino acids are present in different types of pickles, possibly because of the difference in the microbial community during pickle production (Wu et al., 2015).

Finding the relationship between microbiota and metabolites is a powerful approach to understand the dynamics of metabolites during pickle production and to identify the key bacteria necessary for desirable nutrient and sensory contents. This approach has been successful under Lac fermentation conditions (Jeong et al., 2013), and the dynamics of LAB composition correspond to Lac concentrations during pickle production (Yang et al., 2016). The relative abundance of Lactobacillus is negatively correlated with the concentrations of amino acids such as methionine, tyrosine, lysine and arginine (Liu et al., 2020), and the relative abundance of Leuconostoc is positively correlated with the content of acetic acid, butyric acid, cysteine, glycine, isoleucine (Ile) and leucine (Leu) (Xiao et al., 2018). However, the relationship between the microbiota and metabolites in pickles has not been fully evaluated during pretreatment and salt stock preparation. Further studies can illustrate the thorough science of pickle production that has developed since ancient times.

The present study aimed to clarify the changes in microbial composition and concentrations of free amino acids and organic acids by focusing on the processes of independent pretreatment and salt stock preparation that have previously been overlooked. Compared with conditions for Lac fermentation, the pretreatment process uses a similar salt concentration but in the short term. In contrast, salt stock preparation uses a long-term process similar to that for the Lac fermentation process but with a high salt concentration. The results obtained from this study will help to explain the effects of salinity and pickling time on the microbiota as well as the consequent effects of the changed composition of the microbiota on metabolites by comparing the results from the different processing conditions. This will provide valuable knowledge for improving pickle production. Samples were collected from commercial Japanese manufacturers of leafy pickles made from Brassicaceae vegetables. The microbiota were analyzed using 16S rRNA gene sequencing, and 24 free amino acids and organic acids were quantified by liquid chromatography-mass spectrometry (LC-MS). Comparative analysis was used to show that pretreatment of raw materials (short-term pickling at a moderate salinity) results in a microbiota composition more aerobic than that of Lac fermentation. Also, salt stock preparation (long-term pickling at a high salinity) increases the production of branched-chain amino acids (BCAA) by halophilic bacteria, which can be caused by the coenzyme preference of a key enzyme in the BCAA biosynthetic pathway of halophilic bacteria. These results will provide fundamental knowledge on pickling production, which will help to improve the quality of pickles. Also, the 
119 results will expand the possibility to produce the pickles with the desired metabolites by

120 changing the pickling conditions to increase the abundance of target bacteria.

121

122 Materials \& Methods

123 Overview of experimental program

124 A schematic map of the experimental procedures is shown in Figure 1. Briefly, samples of the

125 raw vegetables, pickles and used brine were collected. Bacterial cells were obtained from all

126 samples by centrifugation then their composition was analyzed. The concentrations of free amino

127 acids and organic acids were determined in the samples of homogenized vegetables and pickles,

128 and the used brine. The changes in the $\mathrm{pH}$ and salinity of the process were estimated from the

129 used brine samples. The data were then analyzed statistically.

130

131

Sample collection and processing

132

Samples of traditional Japanese leafy pickles made from Brassicaceae vegetables were provided

133 by eight commercial manufacturers (Manufacturer A to $\mathrm{H}$ ). According to the manufacturer's processes, the initial raw vegetable (Group I), samples from an independent pretreatment process (Group P), or samples from the salt stock preparation process (Group S) were provided. The samples from the pretreatment process and salt stock preparation process included pickled vegetables and used brine (Table 2). The average period for pretreatment was five days, and the average period for the stock preparation process was five months. The pickles were produced between January 2017 and February 2018. The brine samples were used for $\mathrm{pH}$ and salinity measurement. Bacteria for DNA extraction were collected from all samples. Raw and pickled vegetables were cut up under aseptic conditions to provide a total surface area of approximately $140 \mathrm{~cm}^{2}$, then the vegetables were washed vigorously in $10 \mathrm{ml}$ sterile $0.85 \%$ sodium chloride solution for $15 \mathrm{~s}$. The debris was removed from the washing liquid by passing it through a $40 \mu \mathrm{m}$ filter. The filtered solution was centrifuged at $8000 \mathrm{~g}$ and $4{ }^{\circ} \mathrm{C}$ for $10 \mathrm{~min}$, the bacterial cells were collected, and the supernatant was discarded. The cells were collected from the residual brine samples using the same methods of filtering and centrifugation. After cell collection, all samples were stored at $-20^{\circ} \mathrm{C}$ for DNA extraction and further analysis.

\section{DNA extraction and 16S rRNA gene sequencing}

The collected cells were resuspended in lysozyme ( $1 \mathrm{~g} / \mathrm{l}$, Wako Pure Chemicals, Tokyo, Japan) in tris(hydroxymethyl)aminomethane-ethylenediaminetetraacetic acid (Tris-EDTA) buffer and incubated at $37{ }^{\circ} \mathrm{C}$ for $5 \mathrm{~min}$. The DNA was extracted from the processed cells using a Genomic DNA Clean and Concentrator kit (Zymo Research, Irvine, CA, USA). The V3-V4 region of the 16S rRNA gene was PCR-amplified from the extracted DNA using universal primers with Illumina MiSeq (Illumina, San Diego, CA, USA) barcode and adaptor sequences (Mori et al., 2014). The PCR conditions were as follows: one initialization cycle at $94{ }^{\circ} \mathrm{C}$ for $30 \mathrm{~s}$, followed 
159 DNA were analyzed using an Agilent DNA High Sensitivity DNA Kit and an Agilent 2100

160

161

162

163

164

165

166

167

168

169

170

171

172

173

174

175

176

177

178

179

180

181

182

183

184

185

186

187

188

189

190

191

192

193

194

195

196

197

198

Bioanalyzer (Agilent Technologies, Santa Clara, CA, USA), and equimolar amounts of DNA from each sample were loaded into the Illumina MiSeq. The raw fastq files for the 24 samples were deposited in the DDBJ (DNA Data Bank of Japan) under the DRA accession number DRA008404 and were associated with the BioProject titled "Microbiome in Japanese Three Major Leafy Pickles" under the BioProject accession number PRJDB8289.

\section{Measurement of salinity and concentrations of free amino acids and organic acids}

The salinity of the used brine was measured with a LAQUAtwin-Salt-22 ion meter (Horiba, Kyoto, Japan) in at least duplicate. The samples for measuring the concentrations of free amino acids and organic acids by LC-MS were prepared as follows: the raw vegetables and pickles were roughly chopped and approximately $1 \mathrm{~g}$ aliquots were homogenized in an equivalent amount (w:w) of ultra-pure water using a high-power homogenizer (ASONE, Tokyo, Japan) at 3 $000 \mathrm{rpm}$ for $5 \mathrm{~min}$ on ice. The homogenate was centrifuged at $20400 \mathrm{~g}$ and $4{ }^{\circ} \mathrm{C}$ for $5 \mathrm{~min}$, and the supernatant was retained for analysis. Used brine samples were also centrifuged at $20400 \mathrm{~g}$ and $4{ }^{\circ} \mathrm{C}$ for $5 \mathrm{~min}$, and $40 \mu \mathrm{l}$ supernatant was mixed with $10 \mu \mathrm{l}$ internal standard solution (methionine sulfone, $5 \mathrm{~g} / \mathrm{l}$ ). Next, $175 \mu \mathrm{l}$ deproteinization solution (methanol and chloroform, 2.5:1, v:v) was added and mixed vigorously. The mixture was incubated with vigorous shaking at $37^{\circ} \mathrm{C}$ for $30 \mathrm{~min}$, and centrifuged at $20400 \mathrm{~g}$ and $4{ }^{\circ} \mathrm{C}$ for $5 \mathrm{~min}$. Then, $200 \mu 1$ supernatant was mixed with $88 \mu \mathrm{l}$ ultra-pure water and centrifuged at $20400 \mathrm{~g}$ and $4{ }^{\circ} \mathrm{C}$ for $5 \mathrm{~min}$. Finally, $200 \mu 1$ supernatant was mixed with $100 \mu \mathrm{l}$ ultra-pure water passed through a $0.45 \mu \mathrm{m}$ filter to remove the insoluble particles. The final aqueous solutions were analyzed using a LCMS-8050 system (Shimadzu, Kyoto, Japan) with a Discovery HS F5-3 column (Sigma-Aldrich, St Louis, MO, USA). The analysis was performed using the Primary Metabolite Ver. 2 method package (Shimadzu). The conditions for liquid chromatography (Optima LC/MS, Fisher Chemical, Waltham, MA, USA) were as follows: mobile phases, solution A, $0.1 \%$ formic acid in water, solution $\mathrm{B}, 0.1 \%$ formic acid in acetonitrile; flow rate, $0.25 \mathrm{ml} / \mathrm{min}$ with gradient mode; gradient program, 100\% solution A from 0 to $2 \mathrm{~min}, 100 \%-75 \%$ solution A from 2 to $5 \mathrm{~min}, 75 \%-65 \%$ solution A from 5 to $11 \mathrm{~min}, 65 \%-5 \%$ solution A from 11 to $15 \mathrm{~min}$ and 5\% solution from 15 to $20 \mathrm{~min}$; and column oven temperature, $40{ }^{\circ} \mathrm{C}$. The conditions for mass spectrometry were as follows: ionization mode, electrospray ionization; analysis mode, multiple reaction monitoring; nebulizer gas flow rate, $3.0 \mathrm{l} / \mathrm{min}$; drying gas flow rate, $10 \mathrm{l} / \mathrm{min}$; heating gas flow rate, 10 1/min; interface temperature, $300{ }^{\circ} \mathrm{C}$; desolvation line temperature, $250{ }^{\circ} \mathrm{C}$; and heat block temperature, $400{ }^{\circ} \mathrm{C}$. An external standard was used to calculate the concentration of the compound in $\mathrm{mg} / \mathrm{l}$. An internal standard was used to estimate the dilution rate and experimental error. The concentration of each metabolite was transformed into $\mathrm{mg} / \mathrm{kg}$ based on the sample weight. In the case of homogenized solid samples, the weight was calculated based on an assumed density of 1 $\mathrm{g} / \mathrm{ml}$. In the case of liquid samples, the weight was calculated based on the density, which was determined by weighing $1 \mathrm{ml}$ of the sample in at least duplicate. The statistical significance of differences between the mean values of salinity and the concentrations of the free amino acids

Peer] reviewing PDF | (2020:12:56546:1:0:NEW 18 Feb 2021) 
199

200

201

202

203

204

205

206

207

208

209

210

211

212

213

214

215

216

217

218

219

220

221

222

223

224

225

226

227

228

229

230

231

232

233

234

235

236

237

238

and organic acids from two groups out of the I, P and S groups was tested repeatedly using the non-parametric Wilcoxon rank sum test $(P<0.05)$. This test enabled the detection of any significant difference in a single variant dataset without assuming that the data was normally distributed. The Bonferroni correction was applied to avoid any false detection of significant differences due to multiple testing.

\section{Processing $16 \mathrm{~S}$ rRNA gene sequence data for microbiota analysis}

The reads containing N(s) and phiX reads, identified by bowtie2 (version 2.1.0) (Langmead \& Salzberg, 2012), were removed. Unpaired reads were deleted using in-house scripts. The processed reads were filtered, denoised, and merged using the dada2 functions (Callahan et al., 2016 , p. 2) in the R program (version 1.8). In dada2, the forward and reverse reads were truncated to $270 \mathrm{bp}$ and $220 \mathrm{bp}$, respectively, and the primer sequences were trimmed. Reads with a labelled Phred score $<5$ at the first nucleotide or an expected error $>2$ for a forward read and $>5$ for a reverse read were removed (Edgar \& Flyvbjerg, 2015). After the remaining reads were denoised and merged, an amplicon sequence variant (ASV) table (Callahan, McMurdie \& Holmes, 2017) was constructed, and any chimeric reads were removed. The resulting ASV table and reads were imported into QIIME2 (version 2018.11) for further analysis (Bolyen et al., 2018). Default values were used for all optional parameters in the QIIME2 commands. Taxa were assigned to ASVs at the genus level using the Greengenes (version 13.8) database (McDonald et al., 2012), and ASVs for mitochondria and chloroplasts were removed. The reads from genera with average total abundance less than $0.5 \%$ were categorized as "Others." The similarity of the microbiota at the genus level was investigated by principal component analysis (PCA) using R. Beta diversity was analyzed using a built-in function of QIIME 2. Reads from all samples were rarefied to 10477 , which was the smallest read in the dataset, and the distance of the microbiota was calculated using the Bray-Curtis method at the genus level. Any significant differences in microbiota between two groups out of the I, P and S groups were determined using the pairwise permutational multivariate analysis of variance (PERMANOVA) test that enables the detection of significant differences in a multiple variant dataset without assuming a normal distribution. The Benjamini-Hochberg procedure for controlling the False Discovery Rate was applied to avoid any false detection of significant differences due to multiple testing $(q<0.05)$.

\section{Data analysis for estimating metabolic profiles of microbiota}

PICRUSt analysis was performed to evaluate the abundance of metabolic pathways in the microbiota and the contribution of each genus to the pathway abundance using stand-alone PICRUSt2 (version 2.1.4 beta) software (Douglas et al., 2019). Default values for optional parameters were used. Based on MetaCyc classification (Caspi et al., 2018), the pathways from glycolysis, tricarboxylic acid (TCA) cycle, fermentation of pyruvate, fermentation to lactate, alanine biosynthesis, Ile biosynthesis, Leu biosynthesis, valine (Val) biosynthesis, and BCAA biosynthesis were selected. Engineered pathways and pathways from specific genera were excluded. Significant differences in the relative abundance of each pathway among sample

PeerJ reviewing PDF | (2020:12:56546:1:0:NEW 18 Feb 2021) 
239

240

241

242

243

244

245

246

247

248

249

250

251

252

253

254

255

256

257

258

259

260

261

262

263

264

265

266

267

268

269

270

271

272

273

274

275

276

277

278

groups were tested using the Wilcoxon rank sum test $(P<0.05)$ with Bonferroni correction for multiple testing. The total contribution of the genus to the relative abundance of the pathways was calculated, and the genera below the top 10 were categorized as "Others." Further statistical analysis was performed to detect correlations between the relative abundance of genera and the concentrations of free amino acids and organic acids. Genera with a total average of less than $0.5 \%$ were excluded. Significant correlations were determined by the Pearson method using R ( $P$ $<0.05)$.

\section{Results}

\section{Characterization of pretreatment and salt stock preparation samples}

The $\mathrm{pH}$ and salinity of the used brine samples was measured. The $\mathrm{pH}$ of used brine from Group $\mathrm{P}$ and $\mathrm{S}$ was almost same (the average \pm standard deviation; Group P, $7.01 \pm 0.47$; Group S, 6.45 $\pm 0.59)$. The average and standard deviation of the salinity of Group P were $5.3 \% \pm 1.0 \%$, and for Group S they were $17.8 \% \pm 0.2 \%$ (Supplementary Table S1 for raw data). The difference in the salinity between Group P and S was statistically significant. Combined with the information provided by the manufacturers, samples in Group $\mathrm{P}$ were salted to relatively low salinity for short term, and samples in Group S were salted to high salinity for long term.

\section{Difference in microbiota between the process groups}

The analysis of $16 \mathrm{~S}$ rRNA gene sequences indicated differences in the microbiota during pickle production. In total, 4635560 reads were obtained from 24 samples after the mitochondria- and chloroplast-associated reads were removed. The reads represented 4368 ASVs and 742 genera based on the Greengenes database annotation. The average composition of the genera in each process group is shown in Figure 2A (Supplementary Figure S1 for the composition of genus for each sample). The genus Sphingomonas comprised the largest proportion, about $30 \%$, of Group I, followed by Phyllobacterium and Arthorobacter. These three genera, which are often found in soil and the natural environment, formed $49 \%$ of the microbiota of Group I. An unclassified genus of Lactobacillales, an order of LAB, comprised 17\% of Group P. In addition, Pseudoalteromonas and Vibrio, often found in moderately saline environments, formed a relatively high proportion of Group P microbiota. The halophilic genera Halomonas and Halanaerobium constituted approximately $36 \%$ of the bacterial population, and Lactobacillus constituted approximately $15 \%$ in Group S. There were fewer genera in Group S than in Groups I and P. The scatter plot from PCA (Figure 2B) showing the pattern of sample groups indicates that the microbiota was changed by the process. A pairwise statistical test using PERMANOVA indicated that the microbiota of all three groups were significantly different from each other $(q$ value: I vs. P, 0.003; I vs. S, 0.012; P vs. S, 0.012).

\section{Differences in concentrations of free amino acids and organic acids between the groups}

A significantly different microbiota should affect the amount of amino acids and organic acids in the samples. The LC-MS analysis quantified 24 metabolites of free amino acids and organic 
279

280

281

282

283

284

285

286

287

288

289

290

291

292

293

294

295

296

297

298

299

300

301

302

303

304

305

306

307

308

309

310

311

312

313

314

315

316

317

318

acids (Figure 3A, Supplementary Table S2 for raw data). The concentrations of several metabolites were higher in Group $\mathrm{S}$ than in the other groups. Salt stock preparation process was not recognized as a fermentation process, but a considerable amount of Lac was produced: on average, 118 times higher in Group S than in Group I and 48 times higher in Group S than in Group P. Group S showed significantly higher concentrations of Ile ( $P$-value: I vs. S, 0.0002; P vs. S, 0.002), Leu ( $P$-value: I vs. S, 0.0002; P vs. S, 0.0007), phenylalanine ( $P$-value: I vs. S, 0.0002 ; P vs. S, 0.001), Val ( $P$-value: I vs. S, 0.0002; P vs. S, 0.001) and Lac $(P$-value: I vs. S, 0.0002 ; P vs. S, 0.0002) than the other two groups (Figure 2B and Supplementary Table S2). In contrast, Group P showed significantly higher concentrations of only two metabolites, Leu $(P$ value: I vs. P, 0.01) and methionine ( $P$-value: I vs. P, 0.01) than Group I (Figure 3B and Supplementary Table S2), which indicates that the concentrations of the measured metabolites in Group P were generally equivalent to the concentrations in Group I.

\section{The effect of the microbiota in Group $S$ on concentrations of free amino acids and organic acids}

A further analysis was used to identify the relationship between microbiota and metabolites. Among the metabolites that had significantly different concentrations when comparing Group $\mathrm{S}$ and the other two groups, Ile, Leu, Val, and Lac are derivatives of pyruvate based on the generic metabolic pathway (Supplementary Figure S2). Therefore, pyruvate metabolism is expected to be a key in explaining the changes in metabolite concentrations caused by the microbiota. PICRUSt analysis revealed the abundance of pathways related to pyruvate metabolism such as glycolysis, the TCA cycle, and pyruvate fermentation, as well as biosynthetic pathways of Lac, alanine and BCAA (Ile, Leu, and Val; Table 3; Supplementary Table S3 with pathway description), with 25 pathways detected overall. The statistical analysis showed that the abundance of the standard TCA cycle (TCA) was significantly lower in Group S than in Group I ( $P$-value: I vs. S, 0.007). Also, the abundances of all the Lac biosynthetic pathways were higher in Group S than in Group I (Table 3). These results indicate that the microbiota in Group S comprised anaerobic microbes. In contrast, the abundances of pathways for fermentation to lactate in Groups I and P were relatively similar, which reflects the lower concentration of Lac in those groups. The abundance of glycolysis pathways was similar in all groups, possibly because glycolysis is a fundamental pathway for all bacteria. Unexpectedly, the abundances of amino acid biosynthesis pathways in Group $\mathrm{S}$ were not significantly different from those in the other groups, which was not consistent with the results from LC-MS analysis, indicating that the changes in metabolite concentrations were caused by factors other than pathway abundance. PICRUSt 2 contribution analysis was used to identify the genera causing qualitative differences in pathway abundance. Group-specific genera made the highest contribution to the amino acid biosynthetic pathways evaluated (Figure 4): Sphingomonas or Arthrobacter in Group I, Vibrio in Group P, and Halanaerobium in Group S. Halanaerobium may play an important role in the production of Ile, Leu, and Val under high salinity conditions. A correlation analysis confirmed the relationship between the genera and metabolite production. The relative abundances of two 
genera, Halanaerobium and Chromohalobacter, were significantly correlated with the concentrations of Ile, Leu, and Val (Table 4), with higher correlation coefficients between Halanaerobium and metabolite concentrations $(\mathrm{r}=0.71-0.84)$ highlighting the possible relationship.

\section{Discussion}

This study has focused on two processes for producing pickles, pretreatment and salt stock preparation, with the intent of clarifying the effects of the pickling conditions on microbiota and metabolites. The average salinity of the pretreatment group (Group P) was $6 \%$, which is similar to the conditions in previously reported fermentation process (Table 1). Microbiota can be dominated by LAB within three days under moderate salinity conditions (Pérez-Díaz et al., 2020). However, LAB were relatively abundant but not dominant in Group P. The predominance of aerobic genera in Group P suggested that the pickling environment during the pretreatment process was not as anaerobic as the environment during the fermentation process. This may be because strictly anaerobic conditions are not required for pretreated vegetables which will be repickled in the final fermentation environment. The results from the pretreatment process illustrate the effect of inadequately anaerobic conditions on the dominance of LAB in pickle microbiota. In addition, Vibrio, a potentially unfavorable genus for food production, was relatively predominant. This result corresponds to a previous report indicating that salt-cured food can be contaminated with undesired halotolerant microbes (Kim, Cho \& Rhee, 2017). Because Vibrio is a halotolerant and facultative anaerobic genus, it is difficult to eliminate this genus by ambient salinity and anaerobic conditions. Based on the results that the concentrations of free amino acids and organic acids remained the same as in the raw materials during the pretreatment process and $\mathrm{pH}$ was close to neutral, both anaerobic and low $\mathrm{pH}$ environmental conditions, resulting from the fermentation process, should be necessary for safe pickle production under ambient salinity.

The salt stock preparation process did not cause the microbiota to be dominated by LAB but by a mixture of Lactobacillus and the halophilic bacteria Halomonas and Halanaerobium, which was different from the results of previous studies under Lac fermentation conditions (Table 1). Only a limited number of LAB genera can grow under high salinity conditions, which would suppress the dominance of LAB in the salt stock preparation process. The results of the quantification and statistical tests of the metabolites showed that the concentrations of five of the 24 metabolites differed significantly between Group S and the other groups. Of these, four metabolites (Ile, Val, Leu (BCAA), and Lac) are derived from pyruvate based on the generic metabolic pathway (Supplementary Figure S2). Generally, under conditions where aerobic respiration is not available, the TCA cycle is suppressed and pyruvate is used to re-oxidize excess NADH with lactate dehydrogenase to produce Lac. The PICRUSt analysis showed that the TCA cycle was reduced and that Lac biosynthesis was enhanced in Group S, indicating that pyruvate is used to produce Lac under the anaerobic conditions in the salt stock preparation process. It has to be noted that there was a discrepancy between Lac concentration and $\mathrm{pH}$ in salt stock preparation 
359

360

361

362

363

364

365

366

367

368

369

370

371

372

373

374

375

376

377

378

379

380

381

382

383

384

385

386

387

388

389

390

391

392

393

394

395

396

397

samples. Although Lac concentration in Group S was significantly higher than that in Group P, $\mathrm{pH}$ values of Group $\mathrm{P}$ and $\mathrm{S}$ were almost same. Further analysis is needed to clarify the reason for the results but ammonium produced by amino acid catabolism might be the factor to neutralize Lac in salt stock preparation process.

The abundance of the pathway for BCAA biosynthesis, which also originates from pyruvate, remained the same even though BCAA concentrations were significantly increased. The contribution analysis of pathways using PICRUSt showed that the genus with highest contribution was different in each group, which suggests that the pathways had qualitative differences in enzyme activity or substrate affinity and/or selectivity. In Group S,

Halanaerobium had the highest contribution to all pathways for BCAA biosynthesis. Correlation analysis also indicated a significant correlation between the relative abundance of Halanaerobium and the production of BCAA, suggesting that the specific feature of Halanaerobium metabolism resulted in an increase in the pyruvate-family amino acids during the salt stock preparation process. This proposed mechanism is different from that in the fermentation process where LAB produce extracellular peptidase to degrade soluble proteins and increase free amino acids (Liu et al., 2010). The mechanism of how BCAA concentration is increased by Halanaerobium can be explained by the enzymatic character of ketol-acid reductoisomerase (KARI). KARI is a key enzyme in the Ile and Leu/Val biosynthetic pathways (Chen et al., 2018) and is known to use NADPH as a coenzyme (Supplementary Figure S2). Recently, KARI has been reported to enhance the productivity of BCAA by changing the coenzyme selectivity from NADPH to NADH (Brinkmann-Chen, Cahn \& Arnold, 2014). Several species of thermophilic, acidophilic and halophilic bacteria have been found to have KARI which prefers NADH to NADPH. The selectivity of NADH can be caused by four acidic amino acid residues on KARI. The amino acid sequence of KARI in Halanaerobium congolens includes aspartic acid as the second key residue, and the same residue in Desulfococcus oleovorans has been shown to prefer NADH as a coenzyme (Supplementary Figure S3) (Brinkmann-Chen, Cahn \& Arnold, 2014). Some species of Halanaerobium including $H$. congolens may have KARI that uses NADH, which indicates that the BCAA biosynthetic pathway as well as lactate dehydrogenase can re-oxidize NADH. This feature may provide an advantage for maintaining the metabolic redox balance under anaerobic conditions. However, this proposed mechanism is still hypothetical. Isolating the Halanaerobium strain from the samples would allow the investigation of enzymatic profiles and physiological features to clarify the mechanisms between Halanaerobium and BCAA production. The results from such a future study might enable the BCAA content of pickles to be improved by increasing the abundance of specific species of Halanaerobium or bacteria which have the same metabolic features as Halanaerobium.

It should be noted that the present study is not completely comprehensive because the interactions of other bacteria present in the microbiota during pickle production process have not yet been evaluated. This research topic needs further investigation in future studies to clarify the 
398

399

400

401

402

403

404

405

406

407

408

409

410

411

412

413

414

415

416

417

418

419

420

421

422

423

424

425

426

427

428

429

430

431

432

433

434

435

436

437

relationship between the various combinations of bacteria and metabolites to provide a better understanding of the science underlying vegetable fermentation.

\section{Conclusions}

This study has revealed the effects of processing conditions on the microbiota and concentrations of free amino acids and organic acids in pickled vegetables. Pretreatment using a moderate salinity with short-term pickling led to conditions which were not completely anaerobic thus allowing an undesired genus, Vibrio, to become relatively abundant. The experimental results also emphasized the importance of the combination of anaerobic and acidic conditions for assuring safer pickle production. The salt stock preparation conditions using high salinity with long-term pickling caused halophilic bacteria to become predominant. Further analysis has indicated possible relationships between Halanaerobium and BCAA production through a hypothetical metabolic mechanism derived from the preference of coenzyme as a key enzyme in the BCAA biosynthetic pathway. Future studies on identifying bacteria which can produce BCAA under salt stock preparation conditions will provide more precise knowledge on the relationships between microbiota and metabolites during pickle production. The present study has provided an insight into how controlling pickling conditions can change the abundance of bacteria and thus improve the metabolite composition of pickled vegetables.

\section{Acknowledgements}

The samples used in this study were provided by eight commercial pickle manufacturers. ELSI at the Tokyo Institute of Technology assisted with the MiSeq analysis. We thank Tara Penner, MSc, and Philip Creed PhD from Edanz Group (https://en-author-services.edanzgroup.com/ac) for editing a draft of this manuscript.

\section{References}

Bautista-Gallego J, Rantsiou K, Garrido-Fernández A, Cocolin L, Arroyo-López FN. 2013. Salt Reduction in Vegetable Fermentation: Reality or Desire? Journal of Food Science 78:R1095R1100 DOI: $10.1111 / 1750-3841.12170$.

Behera SS, El Sheikha AF, Hammami R, Kumar A. 2020. Traditionally fermented pickles: How the microbial diversity associated with their nutritional and health benefits? Journal of Functional Foods 70:103971 DOI: 10.1016/j.jff.2020.103971.

Bolyen E, Rideout JR, Dillon MR, Bokulich NA, Abnet C, Al-Ghalith GA, Alexander H, Alm EJ, Arumugam M, Asnicar F, Bai Y, Bisanz JE, Bittinger K, Brejnrod A, Brislawn CJ, Brown CT, Callahan BJ, Caraballo-Rodríguez AM, Chase J, Cope E, Silva RD, Dorrestein PC, Douglas GM, Durall DM, Duvallet C, Edwardson CF, Ernst M, Estaki M, Fouquier J, Gauglitz JM, Gibson DL, Gonzalez A, Gorlick K, Guo J, Hillmann B, Holmes S, Holste H, Huttenhower C, Huttley G, Janssen S, Jarmusch AK, Jiang L, Kaehler B, Kang KB, Keefe CR, Keim P, Kelley 
438 ST, Knights D, Koester I, Kosciolek T, Kreps J, Langille MG, Lee J, Ley R, Liu Y-X, Loftfield 439 E, Lozupone C, Maher M, Marotz C, Martin BD, McDonald D, McIver LJ, Melnik AV, Metcalf 440 JL, Morgan SC, Morton J, Naimey AT, Navas-Molina JA, Nothias LF, Orchanian SB, Pearson 441 T, Peoples SL, Petras D, Preuss ML, Pruesse E, Rasmussen LB, Rivers A, Michael S Robeson II, 442 Rosenthal P, Segata N, Shaffer M, Shiffer A, Sinha R, Song SJ, Spear JR, Swafford AD, 443 Thompson LR, Torres PJ, Trinh P, Tripathi A, Turnbaugh PJ, Ul-Hasan S, Hooft JJ van der, 444 Vargas F, Vázquez-Baeza Y, Vogtmann E, Hippel M von, Walters W, Wan Y, Wang M, Warren $445 \mathrm{~J}$, Weber KC, Williamson $\mathrm{CH}$, Willis AD, Xu ZZ, Zaneveld JR, Zhang Y, Zhu Q, Knight R, 446 Caporaso JG. 2018. QIIME 2: Reproducible, interactive, scalable, and extensible microbiome 447 data science. PeerJ 27295v2 DOI: 10.7287/peerj.preprints.27295v2.

448

Brinkmann-Chen S, Cahn JKB, Arnold FH. 2014. Uncovering rare NADH-preferring ketol-acid 450 451 reductoisomerases. Metabolic Engineering 26:17-22 DOI: 10.1016/j.ymben.2014.08.003.

455

456

Callahan BJ, McMurdie PJ, Holmes SP. 2017. Exact sequence variants should replace operational taxonomic units in marker-gene data analysis. The ISME Journal 11:2639-2643 DOI: $10.1038 /$ ismej.2017.119.

457

458

459

460

461

462

463

464

465

466

467

468

469

470

471

472

473

474

475

476

Callahan BJ, McMurdie PJ, Rosen MJ, Han AW, Johnson AJA, Holmes SP. 2016. DADA2: High resolution sample inference from Illumina amplicon data. Nature methods 13:581-583 DOI: $10.1038 /$ nmeth.3869.

Caspi R, Billington R, Fulcher CA, Keseler IM, Kothari A, Krummenacker M, Latendresse M, Midford PE, Ong Q, Ong WK, Paley S, Subhraveti P, Karp PD. 2018. The MetaCyc database of metabolic pathways and enzymes. Nucleic Acids Research 46:D633-D639 DOI: 10.1093/nar/gkx935.

Chakraborty R, Roy S. 2018. Exploration of the diversity and associated health benefits of traditional pickles from the Himalayan and adjacent hilly regions of Indian subcontinent. Journal of Food Science and Technology 55:1599-1613 DOI: 10.1007/s13197-018-3080-7.

Chen C-Y, Ko T-P, Lin K-F, Lin B-L, Huang C-H, Chiang C-H, Horng J-C. 2018. NADH/NADPH bi-cofactor-utilizing and thermoactive ketol-acid reductoisomerase from Sulfolobus acidocaldarius. Scientific Reports 8:7176 DOI: 10.1038/s41598-018-25361-4.

Douglas GM, Maffei VJ, Zaneveld J, Yurgel SN, Brown JR, Taylor CM, Huttenhower C, Langille MGI. 2019. PICRUSt2: An improved and extensible approach for metagenome inference. bioRxiv 672295 DOI: 10.1101/672295. 
477 Edgar RC, Flyvbjerg H. 2015. Error filtering, pair assembly and error correction for next-

478 generation sequencing reads. Bioinformatics 31:3476-3482 DOI:

479 10.1093/bioinformatics/btv401.

480

481

482

Hong SW, Choi Y-J, Lee H-W, Lee J-HY and M-A. 2016. Microbial community structure of

483

484

485

Korean cabbage kimchi and ingredients with denaturing gradient gel electrophoresis. Journal of

Microbiology and Biotechnology 26:1057-1062 DOI: 10.4014/jmb.1512.12035.

486

Jeong SH, Lee SH, Jung JY, Choi EJ, Jeon CO. 2013. Microbial succession and metabolite

487

changes during long-term storage of Kimchi. Journal of Food Science 78:M763-769 DOI:

$10.1111 / 1750-3841.12095$.

488

489

490

Jung JY, Lee SH, Kim JM, Park MS, Bae J-W, Hahn Y, Madsen EL, Jeon CO. 2011.

491

Metagenomic analysis of kimchi, a traditional Korean fermented food. Applied and

492

493

Environmental Microbiology 77:2264-2274 DOI: 10.1128/aem.02157-10.

494

Kim NH, Cho TJ, Rhee MS. 2017. Chapter One - Sodium chloride does not ensure

microbiological safety of foods: cases and solutions. In: Sariaslani S, Gadd GM eds. Advances in

495

Applied Microbiology. Academic Press, 1-47 DOI: 10.1016/bs.aambs.2017.05.001.

496

497

Langmead B, Salzberg SL. 2012. Fast gapped-read alignment with Bowtie 2. Nature Methods

498

9:357.

499

500

Lee M, Song JH, Jung MY, Lee SH, Chang JY. 2017. Large-scale targeted metagenomics

501

analysis of bacterial ecological changes in 88 kimchi samples during fermentation. Food

502

Microbiology 66:173-183 DOI: 10.1016/j.fm.2017.05.002.

503

504

Li J, Hsieh Y-HP. 2004. Traditional Chinese food technology and cuisine. Asia Pacific Journal

505

of Clinical Nutrition 13:147-155.

506

507

Liu M, Bayjanov JR, Renckens B, Nauta A, Siezen RJ. 2010. The proteolytic system of lactic

508

acid bacteria revisited: a genomic comparison. BMC Genomics 11:36 DOI: 10.1186/1471-2164-

509 11-36.

510

511 Liu Z, Peng Z, Huang T, Xiao Y, Li J, Xie M, Xiong T. 2019. Comparison of bacterial diversity

512 in traditionally homemade paocai and Chinese spicy cabbage. Food Microbiology 83:141-149

513 DOI: $10.1016 /$ j.fm.2019.02.012.

514 
515 Liu L, She X, Chen X, Qian Y, Tao Y, Li Y, Guo S, Xiang W, Liu G, Rao Y. 2020. Microbiota 516 succession and chemical composition involved in the radish fermentation process in different

517 containers. Frontiers in Microbiology 11:445 DOI: 10.3389/fmicb.2020.00445.

518

519

520

521

522

523

524

525

526

527

528

529

530

531

532

533

534

535

536

537

538

539

540

541

542

543

544

545

546

547

548

549

550

551

552

553

554
Lupien JR, Lin DX. 2004. Contemporary food technology and its impact on cuisine. Asia Pacific Journal of Clinical Nutrition 13:156-161.

McDonald D, Price MN, Goodrich J, Nawrocki EP, DeSantis TZ, Probst A, Andersen GL, Knight R, Hugenholtz P. 2012. An improved Greengenes taxonomy with explicit ranks for ecological and evolutionary analyses of bacteria and archaea. The ISME Journal 6:610-618 DOI: 10.1038/ismej.2011.139.

McMurtrie EK, Johanningsmeier SD, Breidt F, Price RE. 2019. Effect of brine acidification on fermentation microbiota, chemistry, and texture quality of cucumbers fermented in calcium or sodium chloride brines. Journal of Food Science 84:1129-1137 DOI: 10.1111/1750-3841.14600.

Mori H, Maruyama F, Kato H, Toyoda A, Dozono A, Ohtsubo Y, Nagata Y, Fujiyama A, Tsuda M, Kurokawa K. 2014. Design and experimental application of a novel non-degenerate universal primer set that amplifies prokaryotic $16 \mathrm{~S}$ rRNA genes with a low possibility to amplify eukaryotic rRNA genes. DNA Research 21:217-227 DOI: 10.1093/dnares/dst052.

Pérez-Díaz IM, Dickey AN, Fitria R, Ravishankar N, Hayes J, Campbell K, Arritt F. 2020. Modulation of the bacterial population in commercial cucumber fermentations by brining salt type. Journal of Applied Microbiology 128:1678-1693 DOI: 10.1111/jam.14597.

Pérez-Díaz IM, Hayes J, Medina E, Anekella K, Daughtry K, Dieck S, Levi M, Price R, Butz N, Lu Z, Azcarate-Peril MA. 2017. Reassessment of the succession of lactic acid bacteria in commercial cucumber fermentations and physiological and genomic features associated with their dominance. Food Microbiology 63:217-227 DOI: 10.1016/j.fm.2016.11.025.

Plengvidhya V, Breidt F, Lu Z, Fleming HP. 2007. DNA Fingerprinting of lactic acid bacteria in sauerkraut fermentations. Applied and Environmental Microbiology 73:7697-7702 DOI: 10.1128/aem.01342-07.

Seo S-H, Park S-E, Kim E-J, Lee K-I, Na C-S, Son H-S. 2018. A GC-MS based metabolomics approach to determine the effect of salinity on Kimchi. Food Research International 105:492498 DOI: 10.1016/j.foodres.2017.11.069.

Uthpala TGG, Marapana U, Rathnayake H, Maduwanthi T. 2019. Cucumber vegetable as a brine fermented pickle. In: Chakraborty I, Paul PK, Mani A, Tiwary AK, Prasad K eds. Trends \&

PeerJ reviewing PDF | (2020:12:56546:1:0:NEW 18 Feb 2021) 
555 Prospects in Processing of Horticultural Crops. New Delhi: Today \& Tomorrow's Printers and 556 Publishers, 447-461.

557

558 Wang D, Chen G, Tang Y, Li H, Shen W, Wang M, Liu S, Qin W, Zhang Q. 2020. Effects of

559 temperature on paocai bacterial succession revealed by culture-dependent and culture-

560 independent methods. International Journal of Food Microbiology 317:108463 DOI:

$561 \quad 10.1016 /$ j.ijfoodmicro.2019.108463.

562

563 Wu R, Yu M, Liu X, Meng L, Wang Q, Xue Y, Wu J, Yue X. 2015. Changes in flavour and

564 microbial diversity during natural fermentation of suan-cai, a traditional food made in Northeast

565 China. International Journal of Food Microbiology 211:23-31 DOI:

566 10.1016/j.ijfoodmicro.2015.06.028.

567

568 Xiao Y, Xiong T, Peng Z, Liu C, Huang T, Yu H, Xie M. 2018. Correlation between microbiota 569 and flavours in fermentation of Chinese Sichuan Paocai. Food Research International 114:123570132 DOI: 10.1016/j.foodres.2018.06.051.

571

572 Yang H, Wu H, Gao L, Jia H, Zhang Y, Li ZC and Y. 2016. Effects of Lactobacillus curvatus

573 and Leuconostoc mesenteroides on suan cai fermentation in northeast China. Journal of

574 Microbiology and Biotechnology 26:2148-2158 DOI: 10.4014/jmb.1607.07010.

575

576 Yang H, Zou H, Qu C, Zhang L, Liu T, Wu H, Li Y. 2014. Dominant microorganisms during the 577 spontaneous fermentation of suan cai, a Chinese fermented vegetable. Food Science and

578 Technology Research 20:915-926 DOI: 10.3136/fstr.20.915.

579

580 Zabat MA, Sano WH, Wurster JI, Cabral DJ, Belenky P. 2018. Microbial community analysis of 581 sauerkraut fermentation reveals a stable and rapidly established community. Foods 7:77 DOI:

$58210.3390 /$ foods 7050077.

583 


\section{Table 1 (on next page)}

Brief summary of recent studies on microbiota involved in production of brinefermented vegetables. 
1 Table 1:

2 Brief summary of recent studies on microbiota involved in production of brine-fermented

3 vegetables.

\begin{tabular}{|c|c|c|c|c|c|c|}
\hline $\begin{array}{l}\text { Pickle } \\
\text { name }\end{array}$ & $\begin{array}{l}\text { Raw } \\
\text { material }\end{array}$ & $\begin{array}{l}\text { pickling } \\
\text { solution(s) }\end{array}$ & $\begin{array}{l}\text { Final } \\
\text { salinity }\end{array}$ & $\begin{array}{l}\text { Fermentation } \\
\text { time }\end{array}$ & $\begin{array}{l}\text { Predominant } \\
\text { genus in final } \\
\text { microbiota }\end{array}$ & reference \\
\hline \multirow[t]{2}{*}{ Sauerkraut } & Cabbage & Brine & $2.3 \%$ & $14 d$ & Lactobacillus & $\begin{array}{l}\text { (Plengvidhya et } \\
\text { al., 2007) }\end{array}$ \\
\hline & Cabbage & Brine & $2.25 \%$ & $14 d$ & $\begin{array}{l}\text { Leuconostoc, } \\
\text { Lactobacillus }\end{array}$ & $\begin{array}{l}\text { (Zabat et al., } \\
\text { 2018) }\end{array}$ \\
\hline $\begin{array}{l}\text { Cucumber } \\
\text { pickle }\end{array}$ & Cucumber & Brine & $6 \%$ & $14 d$ & Lactobacillus & $\begin{array}{l}\text { (Pérez-Díaz et al., } \\
\text { 2020) }\end{array}$ \\
\hline \multirow[t]{3}{*}{ Kimchi } & $\begin{array}{l}\text { Chinese } \\
\text { cabbage }\end{array}$ & $\begin{array}{l}\text { Brine with } \\
\text { various spices } \\
\text { and fermented } \\
\text { seafood }\end{array}$ & N.E. & $29 d$ & $\begin{array}{l}\text { Leuconostoc, } \\
\text { Lactobacillus, } \\
\text { Weissella }\end{array}$ & (Jung et al., 2011) \\
\hline & $\begin{array}{l}\text { Chinese } \\
\text { cabbage }\end{array}$ & $\begin{array}{l}\text { Brine with } \\
\text { various spices }\end{array}$ & N.E. & $100 \mathrm{~d}$ & Lactobacillus & $\begin{array}{l}\text { (Jeong et al., } \\
\text { 2013) }\end{array}$ \\
\hline & $\begin{array}{l}\text { Chinese } \\
\text { cabbage }\end{array}$ & $\begin{array}{l}\text { Brine with } \\
\text { various spices }\end{array}$ & $\begin{array}{l}0 \text { and } \\
5 \%\end{array}$ & $50 \mathrm{~d}$ & Leuconostoc & (Seo et al., 2018) \\
\hline \multirow[t]{2}{*}{ Paocai } & Cabbage & $\begin{array}{l}\text { Brine with } \\
\text { various spices }\end{array}$ & $6 \%$ & $7 d$ & Lactobacillus & (Xiao et al., 2018) \\
\hline & Cabbage & Brine & $3 \%$ & $10 \mathrm{~d}$ or $20 \mathrm{~d}$ & Lactobacillus & $\begin{array}{l}\text { (Wang et al., } \\
\text { 2020) }\end{array}$ \\
\hline Suancai & $\begin{array}{l}\text { Chinese } \\
\text { cabbage }\end{array}$ & Brine & $1 \%$ & $30 \mathrm{~d}$ & Lactobacillus & $\begin{array}{l}\text { (Yang et al., } \\
\text { 2014) }\end{array}$ \\
\hline
\end{tabular}


Table 2 (on next page)

Samples used in this study. 


\section{Table 2:}

2 Samples used in this study.

\begin{tabular}{ll}
\hline Group / material & Number of samples \\
\hline Initial raw vegetable (Group I) & \\
Raw vegetable & 8 \\
Pretreatment (Group P) & \\
Processed vegetable & 4 \\
Used brine & 4 \\
$\quad$ Total & $\mathbf{8}$ \\
Salt stock preparation (Group S) & \\
Processed vegetable & 4 \\
Used brine & 4 \\
$\quad$ Total & $\mathbf{8}$ \\
\hline
\end{tabular}

3 


\section{Table 3(on next page)}

The average pathway abundance analysed by PICRUSt.

*, Category and Pathway ID were from the MetaCyc database (https:/metacyc.org/). I, initial raw vegetable group; $\mathrm{P}$, pretreatment group; S, salt stock preparation group; BCAA, branched-chain amino acid. Different superscript letters in a row indicate a significant difference between the mean values $(P<0.05)$. 


\section{Table 3:}

2 The average pathway abundance analysed by PICRUSt.

\begin{tabular}{|c|c|c|c|c|}
\hline \multirow[t]{2}{*}{ Category* } & \multirow[t]{2}{*}{ Pathway ID* } & \multicolumn{3}{|c|}{ Average relative abundance $(\%)$} \\
\hline & & $\mathrm{I}$ & $\mathrm{P}$ & $\mathrm{S}$ \\
\hline \multirow[t]{3}{*}{ Glycolysis } & ANAGLYCOLYSIS-PWY & 0.62 & 0.69 & 0.77 \\
\hline & GLYCOLYSIS & 0.47 & 0.64 & 0.70 \\
\hline & PWY-5484 & 0.47 & 0.64 & 0.68 \\
\hline \multirow[t]{5}{*}{ TCA cycle } & P105-PWY & $0.67^{\mathrm{a}}$ & $0.57^{\mathrm{b}}$ & 0.40 \\
\hline & PWY-5913 & 0.50 & 0.46 & 0.37 \\
\hline & PWY-6969 & $0.69^{a}$ & $0.58^{\mathrm{b}}$ & 0.41 \\
\hline & PWY-7254 & 0.36 & 0.38 & 0.22 \\
\hline & TCA & $0.74^{\mathrm{a}}$ & $0.62^{\mathrm{b}}$ & $0.42^{\mathrm{b}}$ \\
\hline \multirow[t]{5}{*}{ Fermentation of pyruvate } & CENTFERM-PWY & 0.02 & 0.02 & 0.04 \\
\hline & FERMENTATION-PWY & $0.20^{\mathrm{a}}$ & $0.46^{\mathrm{b}}$ & 0.30 \\
\hline & P108-PWY & $0.55^{\mathrm{a}}$ & $0.30^{\mathrm{b}}$ & 0.32 \\
\hline & P161-PWY & $0.08^{\mathrm{a}}$ & 0.24 & $0.56^{\mathrm{b}}$ \\
\hline & PWY-6588 & 0.04 & 0.05 & 0.11 \\
\hline \multirow[t]{4}{*}{ Fermentation to Lactate } & P122-PWY & 0.12 & 0.15 & 0.31 \\
\hline & P124-PWY & 0.21 & 0.19 & 0.42 \\
\hline & P461-PWY & $0.06^{\mathrm{a}}$ & $0.13^{\mathrm{b}}$ & $0.26^{\mathrm{b}}$ \\
\hline & PWY-5100 & 0.18 & 0.21 & 0.64 \\
\hline Ala biosynthesis & PWY0-1061 & 0.31 & 0.52 & 0.43 \\
\hline BCAA biosynthesis & BRANCHED-CHAIN-AA-SYN-PWY & $0.80^{\mathrm{a}}$ & $0.64^{\mathrm{b}}$ & 0.71 \\
\hline \multirow[t]{5}{*}{ Ile biosynthesis } & ILEUSYN-PWY & $0.91^{\mathrm{a}}$ & $0.72^{b}$ & 0.88 \\
\hline & PWY-3001 & $0.67^{\mathrm{a}}$ & $0.57^{\mathrm{b}}$ & 0.64 \\
\hline & PWY-5101 & $0.95^{\mathrm{a}}$ & $0.75^{\mathrm{b}}$ & 0.88 \\
\hline & PWY-5103 & $0.75^{\mathrm{a}}$ & $0.61^{\mathrm{b}}$ & 0.64 \\
\hline & PWY-5104 & 0.40 & 0.43 & 0.49 \\
\hline Val biosynthesis & VALSYN-PWY & $0.91^{\mathrm{a}}$ & $0.72^{\mathrm{b}}$ & 0.88 \\
\hline
\end{tabular}

3 *, Category and Pathway ID were from the MetaCyc database (https:/metacyc.org/). I, initial raw

4 vegetable group; $\mathrm{P}$, pretreatment group; S, salt stock preparation group; BCAA, branched-chain

5 amino acid. Different superscript letters in a row indicate a significant difference between the

6 mean values $(P<0.05)$. 


\section{Table 4 (on next page)}

Significant correlations $(P<0.05)$ between the relative abundance of the genus and the concentrations of isoleucine, leucine or valine. 
1 Table 4:

2 Significant correlations $(P<0.05)$ between the relative abundance of the genus and the

3 concentrations of isoleucine, leucine or valine.

\begin{tabular}{llll}
\hline Genus name & Amino acid & $\begin{array}{l}\text { Correlation } \\
\text { coefficient }\end{array}$ & $P$-value \\
\hline Halanaerobium & Isoleucine & 0.84 & 0.0001 \\
& Leucine & 0.71 & 0.002 \\
& Valine & 0.84 & 0.00004 \\
Chromohalobacter & Isoleucine & 0.57 & 0.022 \\
& Leucine & 0.52 & 0.038 \\
& Valine & 0.52 & 0.038 \\
\hline
\end{tabular}

4 
Figure 1

Schematic map of the experimental procedures used in this study.

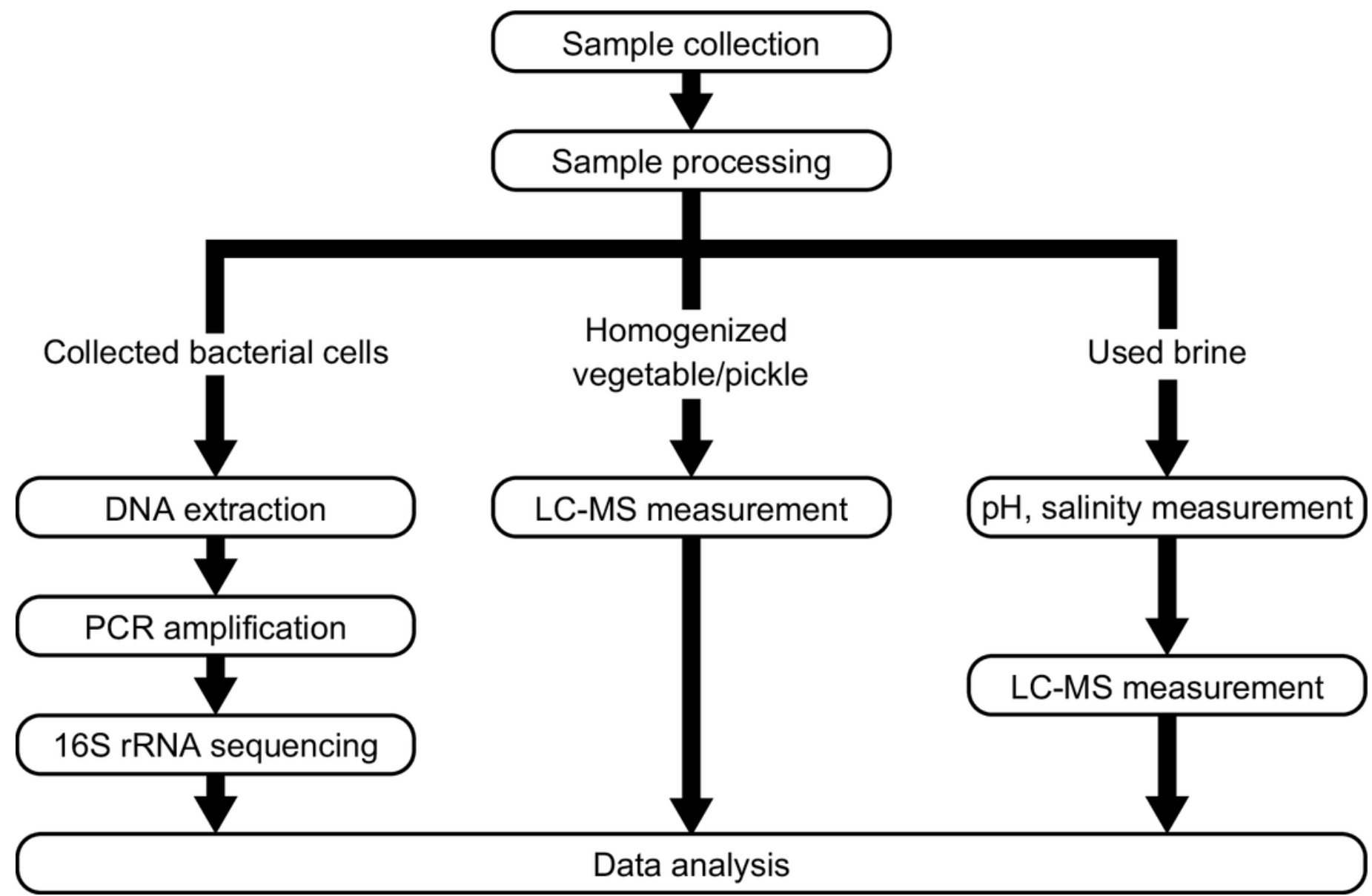


Figure 2

Analysis of microbiota at the genus level during each fermentation process.

A, composition of microbiota. B, scatter plot of PCA. Genera with a total relative abundance of less than $0.5 \%$ are categorized as "Others." I and green circles, initial raw vegetable group $(n=8) ; P$ and blue diamonds, pretreatment group $(n=8) ; S$ and orange triangles, salt stock preparation group $(n=8)$. The 10 most abundant genera were based on the length of the loading vector in the scatter plot.

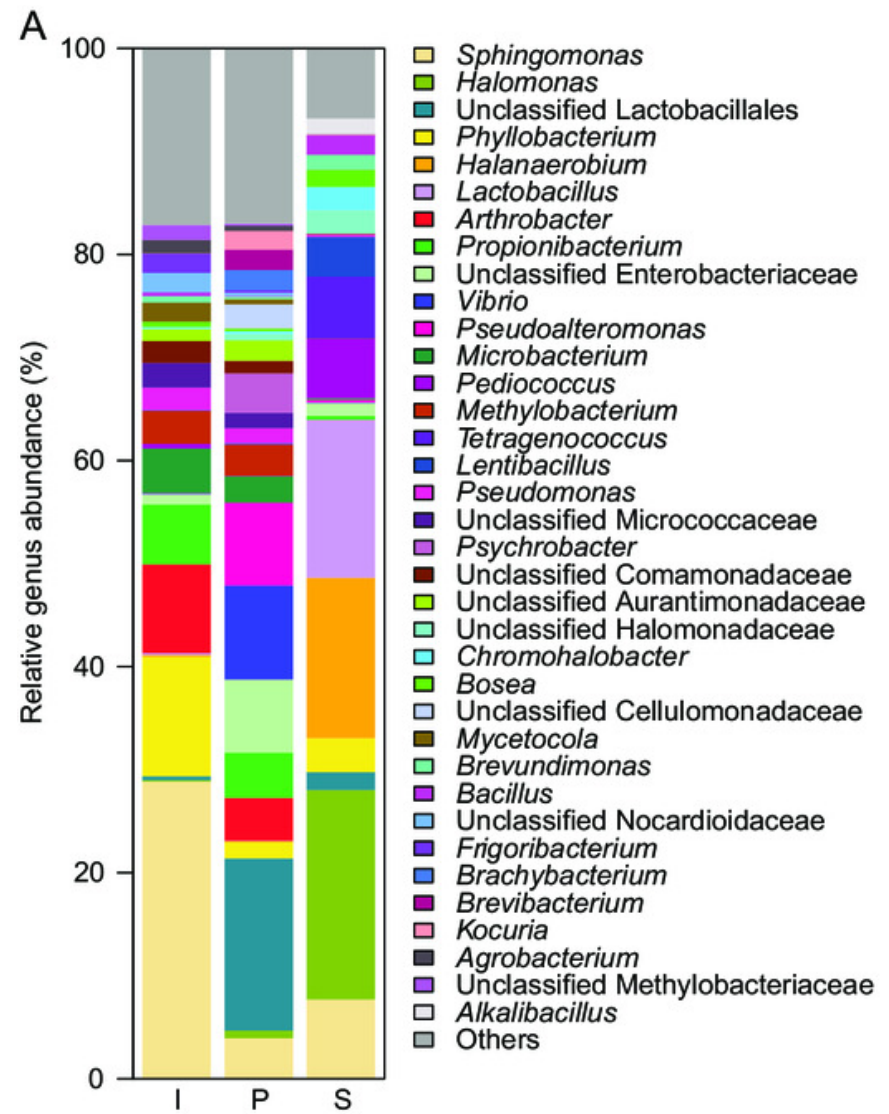

B

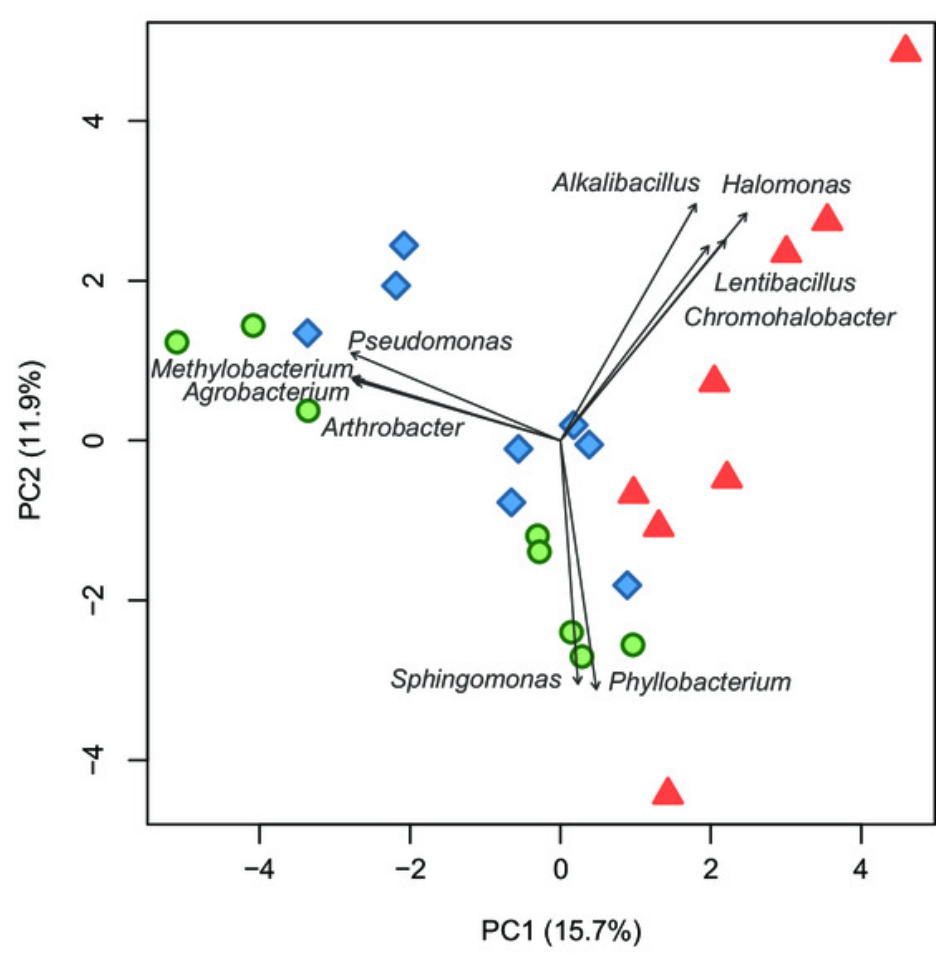




\section{Figure 3}

Concentrations of free amino acids and organic acids.

A, all metabolites measured. B, metabolites with significant difference in average concentrations among the processes. Error bars indicate the standard error. *, significant difference $(P<0.05)$ with Bonferroni correction for multiple testing. I, initial raw vegetable group $(n=8) ; P$, pretreatment group $(n=8) ; S$, salt stock preparation group $(n=8)$. Ala, alanine; Arg, arginine; Asn, asparagine; Asp, aspartic acid; Glu, glutamic acid; Gln, glutamine; Gly, glycine; His, histidine; lle, isoleucine; Leu, leucine; Lys, lysine; Met, methionine; Phe, phenylalanine; Pro, proline; Ser, serine; Thr, threonine; Trp, tryptophan; Tyr, tyrosine; Val, valine; 2KG, 2-ketoglutaric acid; Cit, citric acid; Lac, lactic acid; Pyr, pyruvic acid; Suc, succinic acid. P-values for metabolites with significant difference were as followed: *a, 0.001; *b, 0.001; ${ }^{c}$, $0.0002 ;{ }^{*} d, 0.002 ; * e, 0.0002 ; * f, 0.010 ; *^{g}, 0.007 ; * h, 0.010 ; * j, 0.010 ; *^{k}$, $0.0002 ;{ }^{*} \mathrm{~m}, 0.001 ;{ }^{*} \mathrm{n}, 0.0002 ;{ }^{*} 0,0.001 ; * \mathrm{q}, 0.0002 ;{ }^{*}, 0.0002 ; *^{*}, 0.005$. 
A

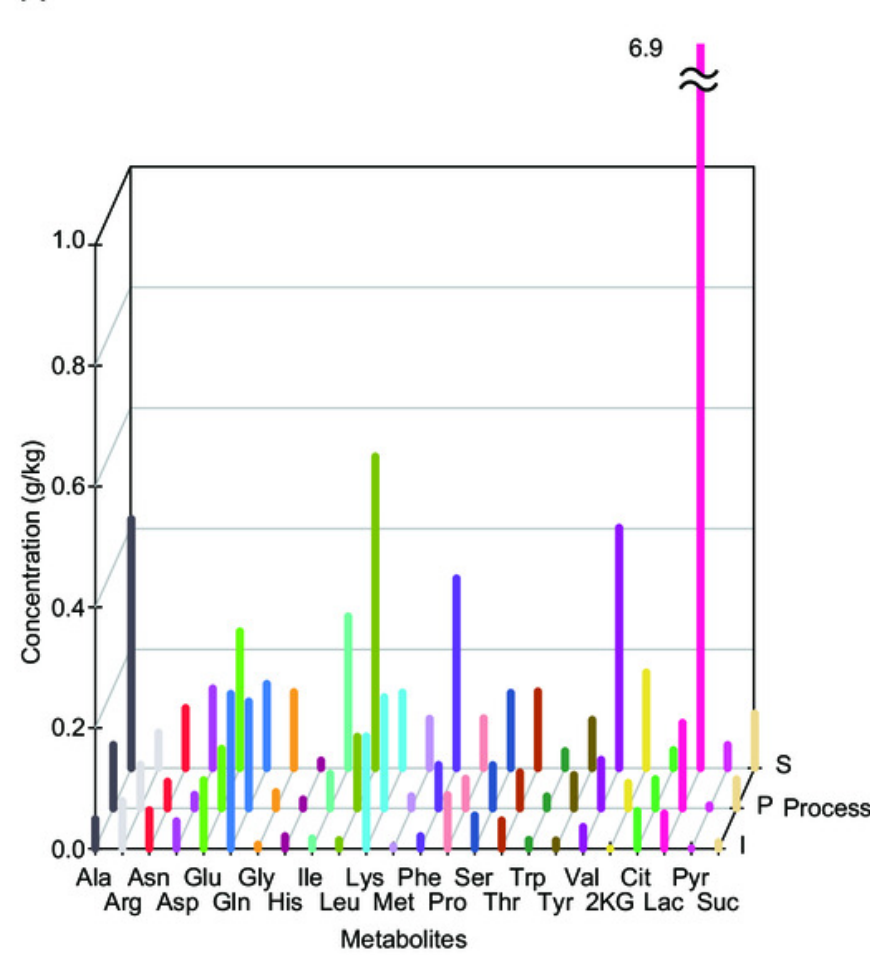

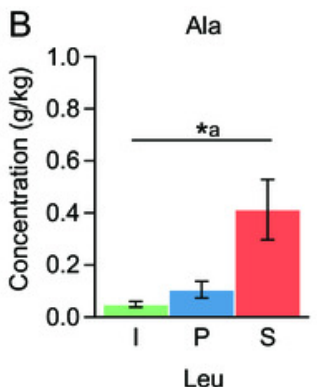
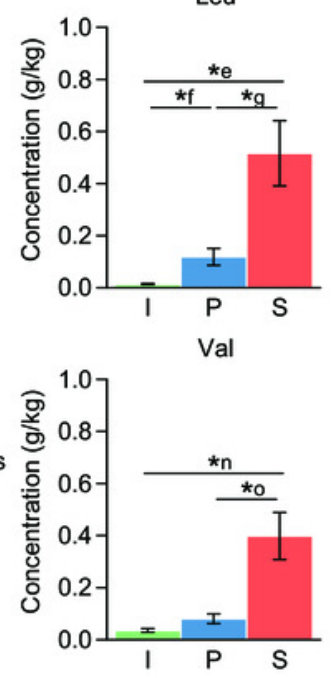

Gly
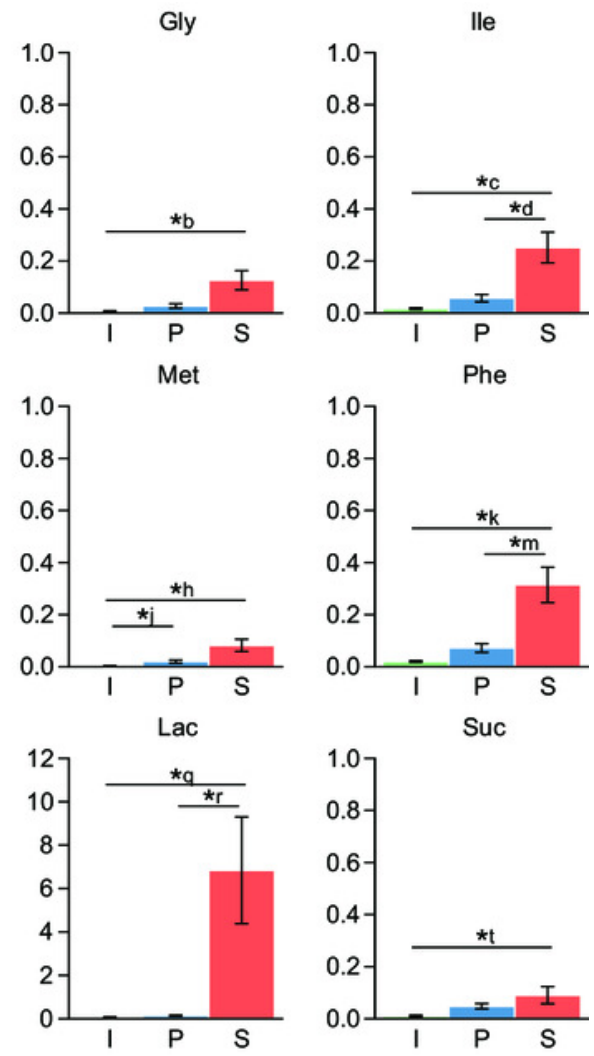


\section{Figure 4}

Contribution of each genus to the abundance of pathways related to BCAA biosynthesis.

Those genera not representing the 10 most abundant were categorized together as "Others." I, initial raw vegetable group $(n=8) ; P$, pretreatment group $(n=8) ; S$, salt stock preparation group $(n=8)$. *, a pathway of BCAA biosynthesis; $\dagger$, pathways of isoleucine biosynthesis; $\ddagger$, a pathway of valine biosynthesis. Contributions to pathway abundances were calculated by multiplying the relative abundance by the copy number of the gene(s).
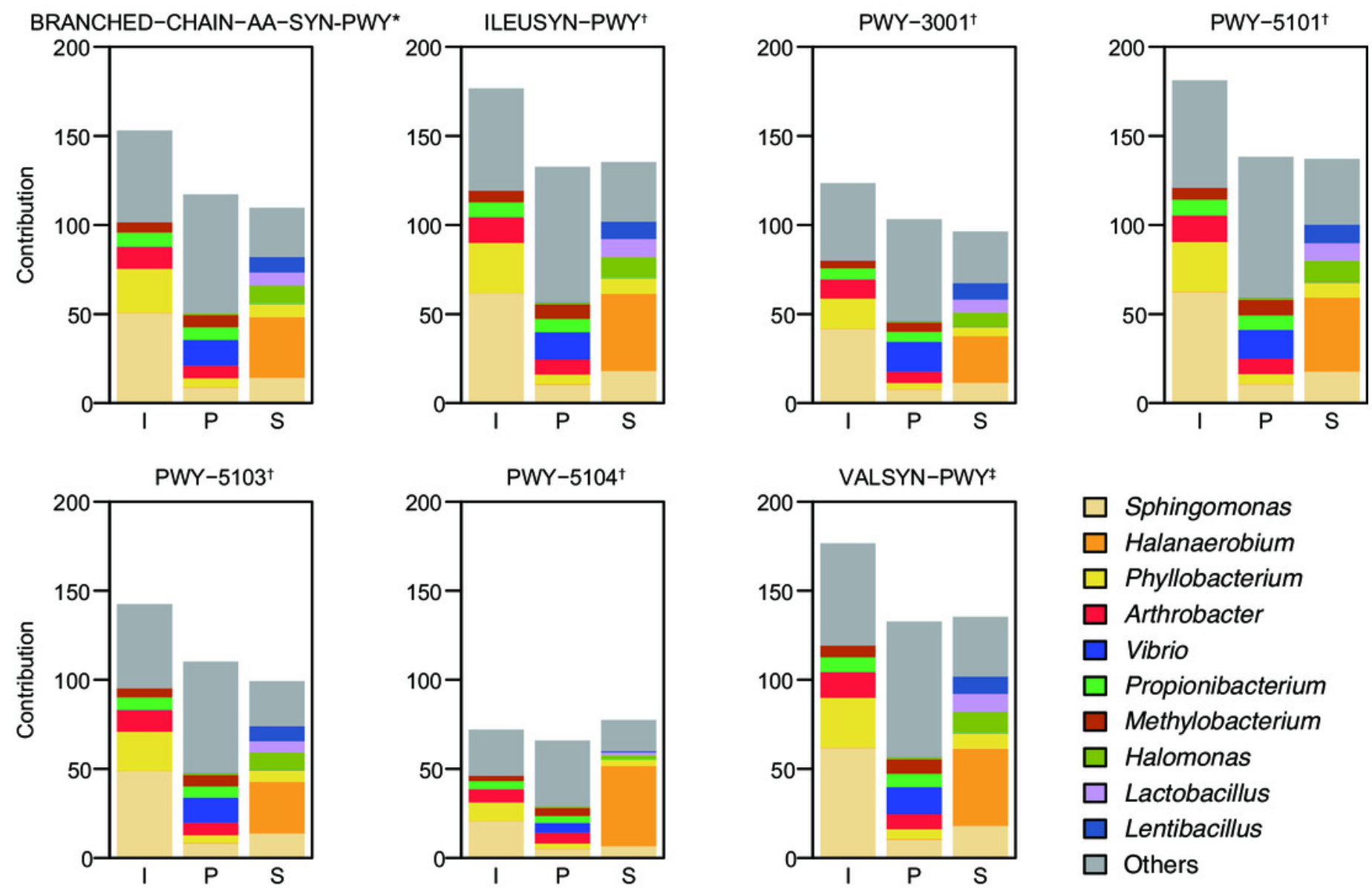

\section{Sphingomonas}

Halanaerobium

Phyllobacterium

$\square$ Arthrobacter

$\square$ Vibrio

$\square$ Propionibacterium

$\square$ Methylobacterium

$\square$ Halomonas

$\square$ Lactobacillus

$\square$ Lentibacillus

$\square$ Others 